\title{
Cyber-Physical Systems: A Framework for Prediction of Error in Smart Medical Devices
}

\author{
Sunday Anuoluwa Idowu ${ }^{1}$, Olawale Jacob Omotosho ${ }^{1}$, Olusegun Ayodeji Ojesanmi ${ }^{2}$, \\ Stephen Olusola Maitanmi ${ }^{1}$ \\ ${ }^{1}$ Department of Computer Science, Babcock University, Ilisan Remo, Ogun State Nigeria \\ ${ }^{2}$ Department of Computer Science, Federal University of Agriculture, Abeokuta, Ogun State, Nigeria
}

\section{Email address:}

saidowu07@gmail.com (S. A. Idowu), ojomotosho1@yahoo.com (O. J. Omotosho), dejioje@yahoo.com (O. A. Ojesanmi), maitanmi@yahoo.com (S. O. Maitanmi)

\section{To cite this article:}

Sunday Anuoluwa Idowu, Olawale Jacob Omotosho, Olusegun Ayodeji Ojesanmi, Stephen Olusola Maitanmi. Cyber-Physical Systems: A Framework for Prediction of Error in Smart Medical Devices. American Journal of Software Engineering and Applications.

Vol. 4, No. 4, 2015, pp. 71-79. doi: 10.11648/j.ajsea.20150404.12

\begin{abstract}
The objective of medical care services is designed to bring improvement to the health of patients. This is pursued with great vigor today with the use of modern health care systems which include medical sensors and automatically controlled actuation to deliver smart and proactive health services. The embedded devices control Smart Medical Devices (SMDs) used by physicians, Nurses, and Medical Staff which continuously interact with the human body or patient in one form or another. Cyber-Physical Systems (CPS) are integrations of computation with physical processes which are monitored and controlled by the embedded systems. CPS has positively affected a number of application areas which include communication, consumer energy, infrastructure, healthcare, manufacturing, military, robotics and transportation. The inappropriate use of these SMDs generate errors which are under-emphasized by stakeholders. Most users are only interested on the benefits derived in the use of SMDs and care-less on the danger that these devices can contribute to patients when used inappropriately. The error tendencies, possible factors and way forward is the subject matter of this paper. In order to achieve the stated objective, Input data was provided through a critical incident analysis of online database which provide readings from medical experts. These readings were compared to the standard world benchmarks and best practices. The difference between the readings and the standard benchmark were used to validate the existence of errors. A framework was developed for error prediction to improve safety in the use of SMDs. Due to the complexity of the problem, an algorithm was further developed to obtain an optimal solution of $\mathrm{P}_{1}$ to $\mathrm{P}_{5}$ within an acceptable threshold runtime which shows the gravity of these challenges on patients.
\end{abstract}

Keywords: Cyber Physical Systems, Embedded System, SMDs

\section{Introduction}

The future of information technology (IT) largely depends on evolving terminologies such as ubiquitous computing, pervasive computing, ambient intelligence, disappearing computer, and post-personal computer (PC) era. Ubiquitous computing reflects the fact that computing and communication will be everywhere. The expectation is that information will be available anytime, anywhere [1]. The intensive involvement of our daily life with computing devices led to the term pervasive computing [2]; [3]. Ambient intelligence refers to some emphasis on communication technology in future homes and smart buildings [4]; [5]. Ubiquitous computing, pervasive computing, and ambient intelligence have diverse application areas. Ubiquitous computing focuses more on the long-term goal of providing information anytime, anywhere, whereas pervasive computing focuses more on practical aspects and the exploitation of already available technology. Disappearing computer refers to the expectation that processors and software will be used in much smaller systems and will, in many cases, even be invisible [1]. While post-PC era denotes the fact that, in the future, standard-PCs will be less dominant hardware platforms. However, disappearing computer entails that processors and software gave rise to embedded systems where processes are highly accelerated not because of the visible components, but by powerful processors. Despite these advancements, almost all 
the technological devices came with their challenges.

Crucial among many pervasive technological tools are the SMDS used in supporting health related researches and medical processes in providing solutions to health care. The inappropriate use of these SMDs generate errors which are under-emphasized by stakeholders. The error tendencies, possible factors and way forward is the subject matter of this research paper.

Error prediction involves the future expectations that error will occur due to some violated rules or metrics. Embedded software is a piece of software that is hidden in a system or hardware components written specifically in a coordinated fashion to achieve an objective. Embedded systems are used in many areas ranging from vehicles and mobile phones to washing machines and printers to increase and enhance productivity.

Cyber-Physical Systems (CPS) are integrations of computation with physical processes which are monitored and controlled by the embedded systems usually with feedback loops where physical processes affect computations [6]. A summary of the CPS application domain is found in Table 1.

Table 1. CPS application domains.

\begin{tabular}{|c|c|c|}
\hline Innovative Products or Applications & Cyber-Physical Systems & Impacts \\
\hline \multicolumn{3}{|l|}{ Smart Manufacturing and Production } \\
\hline $\begin{array}{l}\text { - Agile manufacturing } \\
\text { - Supply chain connectivity }\end{array}$ & $\begin{array}{l}\text { - Intelligent controls } \\
\text { - Process and assembly automation } \\
\text { - Robotics working safely with humans }\end{array}$ & $\begin{array}{l}\text { - Enhanced global competitiveness } \\
\text { - U.S.-based high -tech manufacturing } \\
\text { - Greater efficiency, agility, and reliability }\end{array}$ \\
\hline $\begin{array}{l}\text { Transportation and Mobility } \\
\text { - Autonomous or smart vehicles(surface, air, } \\
\text { water and space) } \\
\text { - Vehicle-to-vehicle and vehicle to } \\
\text { infrastructure communication }\end{array}$ & $\begin{array}{l}\text { - Drive by wire vehicle systems } \\
\text { - Interactive traffic control systems } \\
\text { - Next- generation air transport control }\end{array}$ & $\begin{array}{l}\text { - Accident prevention congestion reduction (zero } \\
\text { fatality highway) } \\
\text { - Greater safety and convenience of travel }\end{array}$ \\
\hline \multicolumn{3}{|l|}{ Energy } \\
\hline $\begin{array}{l}\text { - Electricity systems } \\
\text { - Renewable energy supply } \\
\text { - Oil and gas production } \\
\text { Civil Infrastructure }\end{array}$ & $\begin{array}{l}\text { - Smart electric power grid } \\
\text { - Plug-in vehicle charging systems } \\
\text { - Smart oil and gas distribution grid }\end{array}$ & $\begin{array}{l}\text { - Greater reliability, security, and diversity of energy } \\
\text { supply } \\
\text { - Increased energy efficiency }\end{array}$ \\
\hline $\begin{array}{l}\text { - Bridges and dams } \\
\text { - Municipal water and wastewater treatment }\end{array}$ & $\begin{array}{l}\text { - Active monitoring and control system } \\
\text { - Smart grids for water and wastewater } \\
\text { - Early warning systems }\end{array}$ & $\begin{array}{l}\text { - More safe, secure, and reliable infrastructure } \\
\text { - Assurance of water quality and supply } \\
\text { - Accident warning and prevention }\end{array}$ \\
\hline \multicolumn{3}{|l|}{ Healthcare } \\
\hline - Wireless body area networks & - Medical devices & - Improved outcomes and quality of life \\
\hline - Assistive healthcare systems & - Personal care equipment & - Cost-effective healthcare \\
\hline $\begin{array}{l}\text { - Wearable sensors and implantable devices } \\
\text { Buildings and Structures }\end{array}$ & - Disease diagnosis and prevention & - Timely disease diagnosis and prevention \\
\hline $\begin{array}{l}\text { - High performance residential and commercial } \\
\text { buildings }\end{array}$ & $\begin{array}{l}\text { - Whole building controls } \\
\text { - Smart installed equipment }\end{array}$ & $\begin{array}{l}\text { - Increased building efficiency, comfort and } \\
\text { convenience }\end{array}$ \\
\hline - Net-zero energy buildings & - Building automation systems & - Improved occupant health and safety \\
\hline - Appliances & - Networked appliance systems & - Control of indoor air quality \\
\hline \multicolumn{3}{|l|}{ Defense } \\
\hline - Soldier equipment & - Smart (precision-guided) weapons & - Increased war fighter effectiveness, security, and \\
\hline - Weapons and weapons platforms & - Wearable computing/sensing uniforms & agility \\
\hline - Supply equipment & - Intelligent, unmanned vehicles & - Decreased exposure for human war fighters and \\
\hline - Autonomous and smart underwater sensors & - Supply chain and logistics systems & greater capability for remote warfare \\
\hline Energy Response & & \\
\hline - First responder equipment & - Detection and surveillance systems & - Increased emergency responder effectiveness, safety, \\
\hline - Communications equipment & - Resilient communications networks & efficiency, and agility \\
\hline - Fire-fighting equipment & - Integrated emergency response systems & - Rapid ability to respond to natural and other disasters \\
\hline
\end{tabular}

Source: [7]

This is the era of proliferation of technology where most laborious and herculean works are carried out in a matter of seconds with the help of embedded system. This involves the inbuilt of tiny devices called microprocessors which leads to the increase in smartness and intelligence of automated devices in agriculture, transportation, health sectors and others. Healthcare is one of the areas where advancements in technology remain inestimable through the introduction of embedded systems and CPS. The use of technical equipment such as SMDs is increasing exponentially every year. This extensive use of technology puts large demands on the operators' capabilities to handle the equipment in a proper way. However, this is not true in most cases. There appears to be a number of research issues militating against its successful implementations as outlined below: lack of patient safety measures make medical care unsafe and produce opportunities for medical errors to occur [8] also justified by [9] who stated that 2,000,000 defective devices were recalled in the last decades due to deficiency in outputs. The process of safety began in 1999 with Harvard Medical Practice study that showed adverse events in $3.7 \%$ of hospitalization and errors which could be related to $27.6 \%$ of adverse events [10]. In 2001, the Institute of Medicine published a study tagged 'to err is human: building a safer health system' [11]. This 
study estimated that preventable medical errors are responsible for between 44, 000 and 98,000 deaths annually in United States.

Subsequently, in 2010, the Office of Inspector General for Health and Human Services in Nigeria admitted that bad hospital care contributed to the deaths of 180,000 patients in Medical care alone in a given year. A more heart touching news from the Journal of Patient Safety reports that the numbers may be much higher which was put between 210,000 and 440,000 annually for patients who visit the hospital [12]. Such patients are likely to suffer some type of preventable harm that contributes to their death [12].

However, it is good to mention that this research paper is aimed at proposing a framework to achieve safety and error free in the use of SMDs, paper layout.

The rest of the paper is organized as follows: apart from the introduction section, the next section deals with literature review, methodology of the research paper, results, discussions and conclusion.

\section{Literature Review}

\subsection{Expert System for Reducing Medical Errors}

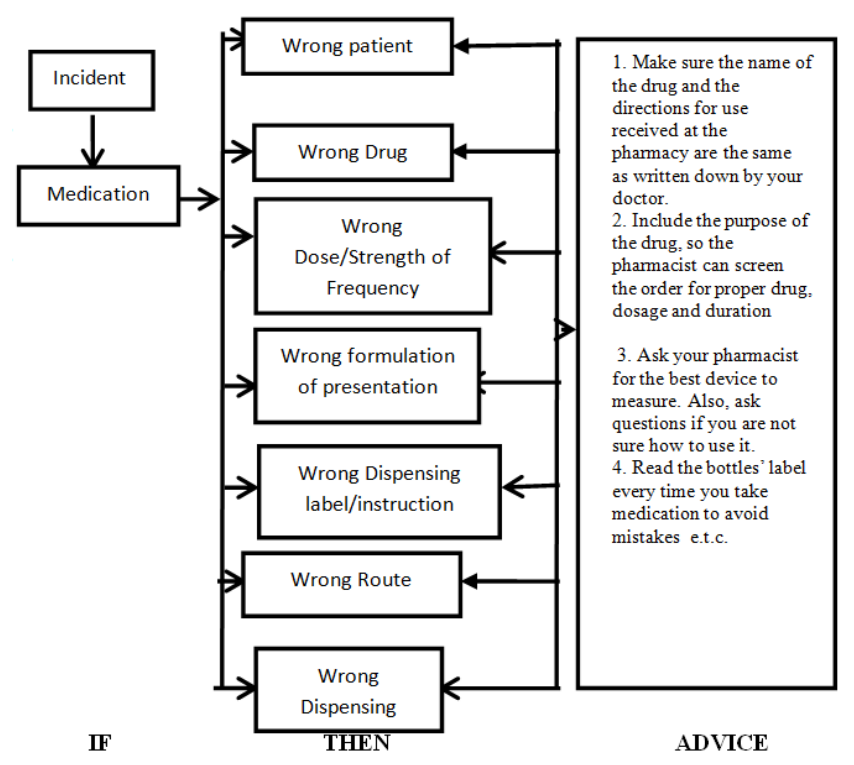

Source: [13]

Figure 1. Expert System for reducing Medical Errors.

The research work carried out by [13] proposed a framework for computer-based medical errors diagnoses of primary systems deficiencies as presented in Fig. 1. Results of this research assisted in developing the hierarchical structure of the medical errors expert system which was written and compiled in CLIPS with numbers of rules. Despite efforts put in place to check users input for consistency within the given limits, it was discovered that error can still be transmitted unknowingly. Medical personnel may lack the knowledge of the right use of the device which are likely to result into error. This is illustrated in Fig. 1

\subsection{Safety Requirements of Infusion Pump-An Example of $S M D$}

In an attempt to ensure safety in infusion pump [14] defines infusion pump as medical devices used to deliver drugs to patients at precise rates and in specific amounts. The authors proposed a Generic Infusion Pump (GIP) model project in an effort to enhance security in the use of infusion pumps. The process of building these formal models started with requirements and hazard analysis which contains the informal requirements and hazard analysis used to create a generic pump model. Their work majors on using models and properties to generate tests which can be used for conformance testing of infusion pump implementations. However, it appears that there are limitation with this method because infusion pump safety was not totally solved and this create a gap in knowledge for other research works.

To further strengthens the trust in the use of infusion pumps, [15] discovered that a combination of faults including software errors, mechanical failures and human error can lead to catastrophic situations; causing death or serious harm to the patient. Dependability analysis techniques such as failure mode effect analysis (FMEA) can be used to predict the worst case outcomes of such faults and facilitate the development of remedies against them. The research work of [15] presented the use of model-checking to automate the dependability analysis of programmable, real-time medical devices.

The challenges faced by medical device manufacturers in bringing safe, reliable, low overall life-cycle cost products to market in a timely manner is increasing rapidly as proposed by [16]. The increasing complexity and criticality of medical devices and the increasing number of safety recalls is driving the need for a good design for reliability (DFR) program in the medical industry. However, theoretical knowledge of a good DFR is not enough.

\subsection{Error Analysis in Anesthesia}

Analysis of error in anesthesia was carried out by [17]. Their outcome stated that human factors constituted the highest degree of anesthesia errors of about $82 \%$ which were known to be preventable, such errors include breathing-circuit disconnections, inadvertent changes in gas flow, and drug syringe errors being frequent problems while only $14 \%$ were caused by equipment failure which include inadequate experience, insufficient familiarity with equipment, inadequate communication among medical staff, lack of precaution and distraction. The authors employed modified critical-incident analysis technique. Their research output is commendable though this direction differs from the existing research paper.

Furthermore, [18] investigated the causes of surgical errors using secondary data obtained from four hospitals. They discovered that System factors contributed to major errors of about $82 \%$ which include inexperience. While technical errors constituted 54\%. They concluded that closed claims analysis can help to identify priority areas for intervening to reduce errors.

In addition, the research carried out by [19] discovered that 
major factors constitute adverse reporting errors in anesthesia.

\section{Methodology}

A critical incident analysis approach was adopted to look into the use of the SMDs because of the sensitivity of the devices. Secondary input data was retrieved from an online database of Medline, Web of Science, Health Technology Assessments and Health and Science Care Information Center which provides database of readings from medical experts. The SMDs analysed in this research paper include thermometer, sphygmomanometer, infusion pump and insulin pump. These SMDs were chosen because of their relevance in the implementation of CPS as regards technological advancement to health care systems. These readings were further compared with the standard world benchmarks. The readings also served as input to the framework for error prediction. Due to the complexity of the problem, an algorithm was further developed to obtain an optimal solution of $\mathrm{P}_{1}$ to $\mathrm{P}_{5}$ within an acceptable threshold runtime which shows the effects of the problem on patients.

\subsection{Thermometer for Both Benchmark and Readings}

The following represent the analysis of digital thermometer:
Table 2. Temperature readings and standard benchmark $\left({ }^{\circ} \mathrm{C}\right)$ Source : Appendix A-C.

\begin{tabular}{lllll}
\hline Symptoms & Benchmark (P) & Time(t) & Readings P(t) & Error(t) \\
& 37.9 & 0 & 37.9 & 0 \\
Malaria & 38.5 & 10 & 36.0 & 2.5 \\
& 38.7 & 20 & 36.1 & 2.6 \\
& 38.9 & 30 & 36.2 & 2.7 \\
& 39.5 & 40 & 36.3 & 3.2 \\
& 39.6 & 50 & 36.3 & 3.3 \\
& 37.7 & 0 & 37.7 & 0 \\
URTI & 38.5 & 10 & 37.7 & 0.8 \\
& 39.0 & 20 & 37.8 & 1.2 \\
& 39.5 & 30 & 37.9 & 1.6 \\
& 39.8 & 40 & 38.0 & 1.8 \\
& 40.0 & 50 & 38.0 & 2.0 \\
Tonsilitis & 36.4 & 0 & 36.4 & 0 \\
& 37.8 & 10 & 36.5 & 0.4 \\
& 39.2 & 20 & 37.0 & 2.2 \\
& 39.9 & 30 & 37.6 & 2.3 \\
& 40.0 & 40 & 38.0 & 2.0 \\
Severe Head & 40.5 & 50 & 38.5 & 2.0 \\
Injury & 39.8 & 0 & 39.8 & 0 \\
& 40.9 & 10 & 39.8 & 0.1 \\
& 43.5 & 20 & 39.9 & 0.6 \\
& 45.5 & 30 & 40.0 & 3.5 \\
& 47.5 & 40 & 40.0 & 5.5 \\
Septicaemia & 49.9 & 50 & 40.1 & 7.4 \\
& 40.0 & 0 & 39.9 & 0 \\
& 47.3 & 10 & 39.0 & 1.0 \\
& 47.8 & 20 & 39.5 & 5.8 \\
& 48.0 & 30 & 39.9 & 7.4 \\
& & 40 & 40.0 & 7.8 \\
& 50 & 40.0 & 8.0 \\
\hline
\end{tabular}

Where URTI= upper respiratory tract infection.

Table 3. Sphygmomanometer readings and standard Benchmark (mmhg) Appendix D.

\begin{tabular}{llllll}
\hline Systolic & & Diastolic & & & \\
\hline & BM/RD/error & BM/RD/error & BM/RD/error & BM/RD/error & BM/RD/error \\
\hline & $\mathbf{8 4}$ & $\mathbf{8 5 - 8 9}$ & $\mathbf{9 0 - 9 9}$ & $\mathbf{1 0 0 - 1 0 9}$ & $\mathbf{1 1 0 - 1 1 9}$ \\
\hline$\leq 129$ & 211 & 321 & 431 & 541 & 651 \\
$<130-139$ & 220 & 321 & 431 & 541 & 651 \\
$<140-159$ & 330 & 330 & 431 & 541 & 651 \\
$<160-179$ & 541 & 541 & 431 & 541 & 651 \\
$<180-209$ & 550 & 550 & 541 & 651 & 651 \\
$\geq 210$ & 761 & 660 & 541 & 761 & 761 \\
\hline
\end{tabular}

Where $\mathrm{N}=161, \mathrm{BM}=$ benchmark and $\mathrm{RD}=$ readings

\subsection{Infusion Pump for Both Benchmark and Readings}

Table 4. Infusion Pump readings and standard Benchmark (msl/hr.) Source: [20].

\begin{tabular}{llll}
\hline Benchmark & Readings & Error & Time (Mins) \\
\hline Adult $-100 \mathrm{mls} / \mathrm{hr}$ & $80 \mathrm{mls} / \mathrm{hr}$ & 10 & 60 \\
$500 \mathrm{mls} / \mathrm{hr}$ & $480 \mathrm{mls} / \mathrm{hr}$ & 20 & 60 \\
$500 \mathrm{mls} / \mathrm{hr}$ & $490 \mathrm{mls} / \mathrm{hr}$ & 10 & 60 \\
4 litres/day & 4 litres/day & 0 & 1,440 \\
$500 \mathrm{mls} / 12 \mathrm{rs}$ & $480 \mathrm{mls} / 12 \mathrm{rs}$ & 20 & 720 \\
$500 \mathrm{mls} /$ day & $495 \mathrm{mls} / \mathrm{day}$ & 5 & 1,440 \\
Children 300mls/day & $280 \mathrm{mls} /$ day & 20 & 1,440 \\
$10 \mathrm{mls} / \mathrm{hr}$ & $10 \mathrm{mls} / \mathrm{hr}$ & 0 & 60 \\
1 liter/day & 1 litre/day & 0 & 1,440 \\
2 litres/day & 2 litres/day & 0 & 1,440 \\
\hline
\end{tabular}




\subsection{Insulin Pump for Both Benchmark and Readings}

Table 5. Insulin Pump readings and standard Benchmark

\begin{tabular}{|c|c|c|c|c|c|}
\hline Time & Benchmark Blood Glucose & Amount of Carbohydrates & Benchmark Insulin intake & Readings Insulin intake & Errors \\
\hline \multicolumn{6}{|l|}{ Day 1} \\
\hline 7:30am & 5.7 & $60 \mathrm{~g}$ & 4 & 8 & 4 \\
\hline $1: 30 \mathrm{pm}$ & 11.2 & $50 \mathrm{~g}$ & 3.3 & 6.6 & 3.3 \\
\hline $6: 00 \mathrm{pm}$ & 7.2 & $72 \mathrm{~g}$ & 5 & 10 & 5 \\
\hline $10: 00 \mathrm{pm}$ & 8 & & & & \\
\hline \multicolumn{6}{|l|}{ Day 2} \\
\hline 7:30am & 6.8 & $60 \mathrm{~g}$ & 4 & 8 & 4 \\
\hline $1: 30 \mathrm{pm}$ & 12.3 & $50 \mathrm{~g}$ & 3.3 & 6.6 & 3.3 \\
\hline $6: 00 \mathrm{pm}$ & 7.1 & $90 \mathrm{~g}$ & 6 & 12 & 6 \\
\hline $10: 00 \mathrm{pm}$ & 11.3 & & & & \\
\hline
\end{tabular}

1 unit of insulin for every $15 \mathrm{~g}$ Carbohydrates taken. Insulin Pump Workbook. Source: [21].

\subsection{Algorithm Development}

Relationship between Model and Thermometer table

Performance at optimum level is represented in Table 3.1 as the Benchmark of temperature taken when error is not involved $(\mathrm{P})$ which is equivalent to $100 \%$.

Performance with respect to time is represented in Table 3.1 taking note of the time in minutes when temperatures were taken $\mathrm{P}(\mathrm{t})$. The recorded time were decimated to reduce the magnitudes of error such as $0.1,0.2,0.3$ and so on for Malaria. These values are not constant for other ailments.

Error as shown in Table 3.1 gives the difference between benchmark and actual readings which was also decimated to reduce error value thereby realizing (E) of Malaria to be 0.25 , $0.26,0.27,0.32$ and 0.33

$P^{1}=$ the change in performance over the change in time of measurement

P1-P5 is the performance level of the SMDs and the model with respect to the introduced error.

$P=$ Performance at optimum level

$P(t)=$ Performance with respect to $\mathrm{t}$

$E(t)=$ Error introduced at any time $\mathrm{t}$

$$
P(t)=P-E(t)
$$

Equation 3.4.1 gives the difference between the benchmark and the actual reading which is a function of time.

$$
P^{1}(t) \propto E(t) P(t)
$$

$P^{1}(\mathrm{t})$ is the change in performance which is proportional to the product of performance and the error at any time $\mathrm{t}$

$$
\begin{gathered}
P^{1}(t)=-K E(t) P(t) \\
P^{1}(t)=-E(t) P(t)
\end{gathered}
$$

Substituting $P(t)$ in (3.4.1) gives

$$
\begin{aligned}
& P^{1}(t)=-E(t)[P-E(t)] \\
& P_{n+1}=P_{n}+h\left(P^{1}\right)_{n} .
\end{aligned}
$$

(Euler's representation)

Declarations

Step 1: Initialize fractional variables (double) $h, t, E$
Step 2: Initialize whole numbers (Int) $P, n$

Step 3: let all values of $\mathrm{n}$ be between 0 to 4

Step 4: Let $\mathrm{E} 0=0.25, \mathrm{E} 1=0.26, \mathrm{E} 2=0.27, \mathrm{E} 3=0.32$ and $\mathrm{E} 4=1.85$

Step 5: Let 0.1 be stored in $\mathrm{t}$ as fractional number

Step 6: Let 1 be stored in $\mathrm{P}$ as whole number

Step 7: Let 0.1 be stored in $\mathrm{h}$ as fractional number

Starting the Euler's iterations

Step 8: making reference to step (4) substituting it in equation (3.4.2) where $\left(P^{1}\right)_{0}=-E_{0}(t)\left[P-E_{0}(t)\right]$ Find $\left(P^{1}\right)_{0}$ to $\left(P^{1}\right)_{4}$

Step 9: starting iteration where the values of $n=0$ to 4 starting with $\mathrm{n}=0$ to begin

$$
P_{1}=P_{0}+h\left(P^{1}\right)_{0} \text { store the result in } P
$$

Step 10: Use the value obtained above in step 8 on $\left(P^{1}\right)_{1}$ to find $P_{2}=P_{1}+h\left(P^{1}\right)_{1}$ and store the result in $P_{2}$

Step 11: Use the value obtained above in step 8 on $\left(P^{1}\right)_{2}$ to find $P_{3}=P_{2}+h\left(P^{1}\right)_{2}$ and store the result in $P_{3}$

Step 12: Use the value obtained above in step 8 on $\left(P^{1}\right)_{3}$ to find $P_{4}=P_{3}+h\left(P^{1}\right)_{3}$ and store the result in $P_{4}$

Step 13: Use the value obtained above in step 8 on $\left(P^{1}\right)_{4}$ to find $P_{5}=P_{4}+h\left(P^{1}\right)_{4}$ and store the value in $P_{5}$

Step 14: Display the values of $P_{1}, P_{2}, P_{3}, P_{4}, P_{5}$

\section{Results and Discussions}

\subsection{Algorithm Interpretation}

If the figures of $\mathrm{E} 0=0.25, \mathrm{E} 1=0.26, \mathrm{E} 2=0.27, \mathrm{E} 3=0.32$ and $\mathrm{E} 4=1.85$ are appropriately slotted into the equation as the indicated errors from the algorithm, also if $\left(P^{1}\right)_{0}$ to $\left(P^{1}\right)_{4}$ are adequately calculated. Then P1to P5 will be given as $99.8 \%, 99.5 \%, 99,2 \%, 98.9 \%$ and $98.6 \%$ accuracy in measurements. These values indicated that P1 to $\mathrm{p} 5$ refers to percentage analysis of the performance of the predicted error, the higher the error, the lower the performance of the SMDs which will have adverse effects on patients who are meant to 
have maximum performance without errors.

\subsection{Framework}

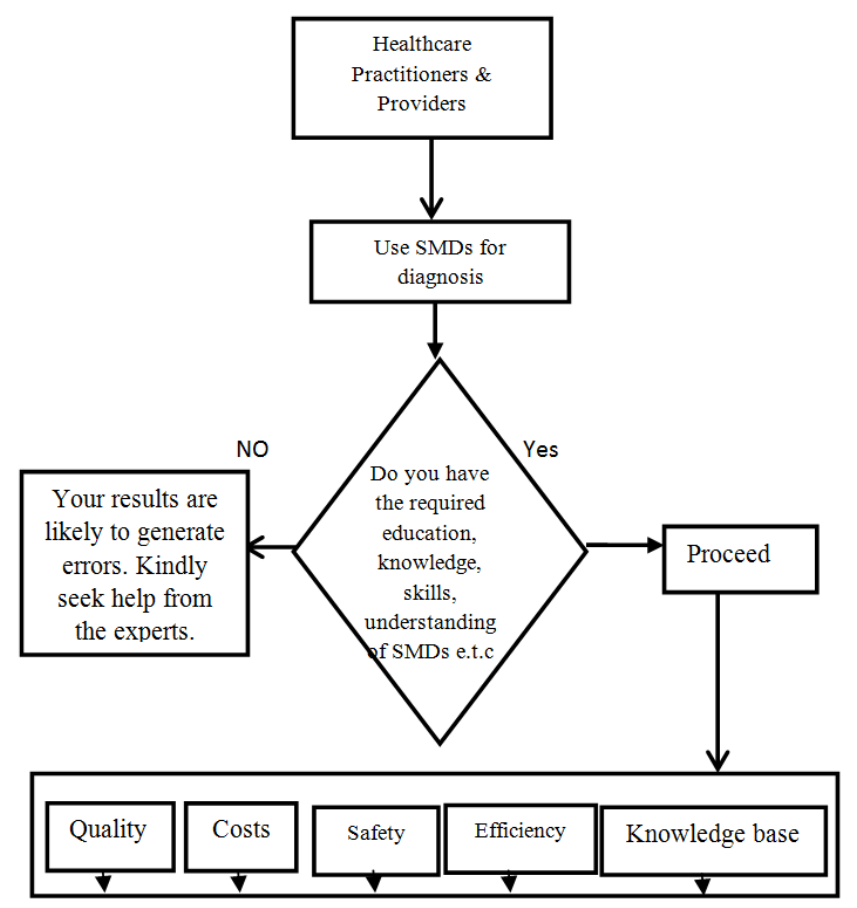

Figure 2. Proposed Framework for Safety and Verification of SMDs.

Tables 2-5 has shown clearly that there is the possibility of committing errors when the SMDs are used inappropriately. However, in an attempt to resolve these errors, we developed a framework in Fig. 2 which consists of the usage and administration of SMDs with respect to the embedded systems and CPS. It may also be referred to as a window that predicts the existence of error in the use of SMDs. Such errors and its effects might prevent individual users from committing errors by either having the right educational experience to guide them, read prescription extensively or meet others for more understanding in case of doubt.

The framework consists of healthcare practitioners or providers that are willing and ready to take care of patients with the advancement of healthcare innovations such as embedded systems and CPS. If these innovations were adequately understood with adequate knowledge of SMDs, it will affect the patients positively in diagnosis. This will improve the quality of treatment, reduce the cost of further treatments, increase safety, improve efficiency and provide knowledge base for future diagnosis. However, if the healthcare providers flout these principles, there is likelihood that error may be generated in the result. Therefore, the medical personnels are expected to seek help through sufficient and updated training in the use of the SMDs.

\section{Conclusion}

Conclusively, it has been discussed that CPS is a growing area of research with an evolving number of application domains in particular health care systems. This research paper has predicted with the aid of algorithm and framework the possibility that error can occur if SMDs are used inappropriately. This effects can prolong the stay of patients in hospital, prolong their healing time or even cause permanent damage.

\section{Acknowledgement}

I will like to appreciate Mr. Semiu Ayinde of the department of Basic Sciences, Babcock University, the Head of Department of Radiology, Babcock University Teaching Hospital (BUTH) Dr. Yusuf, Adebola and one of his vibrant staff, Dr. Ajiboye, Bimpe who contributed immensely to the completion of this research paper.

\section{Appendix A: Temperature Measurement}

\section{Fever in adults}

If you or a family member has a fever, it means your body temperature is above normal.

Around $37^{\circ} \mathrm{C}$ is normal

A digital thermometer is the best type to use to get an accurate temperature reading.

A fever is usually a normal response of your immune system to a virus or bacterial infection. Most healthy adults can tolerate a fever well.

Fever ranges and symptoms

$38-38.9^{\circ} \mathrm{C}$ - mild fever

With a mild fever you might have flushed cheeks, feel a little lethargic, and be warm to touch. You will generally be able to carry out normal daily activities.

\section{$39-39.9^{\circ} \mathrm{C}-$ high fever}

With a high fever you may not feel well enough to go to work, you may have aches and pains, and you'll feel hot to touch.

$40^{\circ} \mathrm{C}$ or higher - very high fever

With a very high fever you will usually want to stay in bed or be inactive - you won't feel well enough to carry out normal activities. You may have lost your appetite. You'll feel hot to touch.

\section{When to see your doctor}

Some mild diseases produce very high fevers - and severe illnesses can produce mild fever. Therefore, when considering what medical attention you need, it's important to look at other symptoms and how unwell you feel.

You should see your doctor if you or a family member:

- has a very high fever (over $40^{\circ} \mathrm{C}$ )

- is still feverish after three days of home treatment, or seems to be getting sicker

- is shivering or shaking uncontrollably, or has chattering teeth

- has a severe headache that doesn't get better after taking painkillers

Appendix $A$

- is having trouble breathing

- is getting confused or is unusually drowsy 
- has recently travelled overseas.

When it's urgent

See your doctor or go to the Emergency Department immediately if you notice the following symptoms (along with a fever):

- Hallucinations

- Vomiting

- A stiff neck (they're unable to put their chin on their chest or have pain when moving their neck forward)

- A skin rash

- A rapid heart rate.

Also get medical help if the person has a seizure (fit), or has signs of a seizure about to happen, such as regular twitching or jerking.

Call Healthline 0800611116 if you are unsure what you should do.

Fever in pregnancy

If you're pregnant and have a temperature of $38.5^{\circ} \mathrm{C}-$ or any fever lasting for three days or more - you must see your lead maternity carer. They'll need to monitor the effects of the fever on your baby.

Self care

Most fevers last only three to four days - and a mild fever may not need any treatment at all.

Try these ideas if your fever is mild and you don't have any other worrying symptoms:

- Drink plenty of fluids - water is best.

- Get plenty of rest.

- Wear light weight clothes and use lighter bedding. Keep the room temperature normal.

- Put cool cloths on your face, arms and neck to help you cool down. Don't use any rapid cooling methods that may make you shiver. (The muscle movement in shivering will actually raise your temperature and can make your fever worse.)

\section{Appendix B: Temperature Measurement}

Fever and Night Sweats

Fever is a common sign that on its own is usually little help in making a diagnosis. Persistent high fever needs urgent treatment. Fever over $42.2^{\circ} \mathrm{C} \quad\left(108^{\circ} \mathrm{F}\right)$ producesunconsciousness and leads to permanent brain damage if sustained. Fever can be classified as:

- Low: $37.2-38^{\circ} \mathrm{C}\left(99^{\circ}-100.4^{\circ} \mathrm{F}\right)$.

- Moderate: $38.1-40^{\circ} \mathrm{C}\left(100.5^{\circ}-104^{\circ} \mathrm{F}\right)$.

- High: $>40^{\circ} \mathrm{C}\left(104^{\circ} \mathrm{F}\right)$.

Fever may also be described as:

- Remitting - the most common type with daily temperatures fluctuating above the normal range.

- Intermittent - daily temperature drops into the normal range and then rises back above normal. If temperature fluctuates widely causing chills and sweating, it is called a hectic fever.

- Sustained - persistent raised temperature with little fluctuation.

- Relapsing - alternating feverish and a febrile periods.
- Undulant - gradual increase in temperature, which stays high for a few days then gradually reduces.

Fever may also be described in terms of its duration; brief ( $<3$ weeks), or prolonged. The term pyrexia of unknown origin (PUO) is used to describe a condition where no underlying cause can be found. ${ }^{[1]}$ Night sweats are common and there is a long list of possible causes, mostly benign but important to diagnose in order to manage effectively. Serious causes of night sweats can usually be excluded by a thorough history, examination and simple investigations if required. ${ }^{[2]}$

\section{Appendix C: Body Temperature}

What is body temperature?

Body temperature is a measure of the body's ability to generate and get rid of heat. The body is very good at keeping its temperature within a narrow, safe range in spite of large variations in temperatures outside the body.

When you are too hot, the blood vessels in your skin expand (dilate) to carry the excess heat to your skin's surface. You may begin to sweat, and as the sweat evaporates, it helps cool your body. When you are too cold, your blood vessels narrow (contract) so that blood flow to your skin is reduced to conserve body heat. You may start shivering, which is an involuntary, rapid contraction of the muscles. This extra muscle activity helps generate more heat. Under normal conditions, this keeps your body temperature within a narrow, safe range.

Where is body temperature measured?

Your body temperature can be measured in many locations on your body. The mouth, ear, armpit, and rectum are the most commonly used places. Temperature can also be measured on your forehead.

What are Fahrenheit and Celsius?

Thermometers Fiol are calibrated in either degrees Fahrenheit $\left({ }^{\circ} \mathrm{F}\right)$ or degrees Celsius $\left({ }^{\circ} \mathrm{C}\right)$, depending on the custom of the region. Temperatures in the United States are often measured in degrees Fahrenheit, but the standard in most other countries is degrees Celsius.

What is normal body temperature?

Most people think of a "normal" body temperature as an oral temperature of $98.6^{\circ} \mathrm{F}\left(37^{\circ} \mathrm{C}\right)$. This is an average of normal body temperatures. Your temperature may actually be $1^{\circ} \mathrm{F}\left(0.6^{\circ} \mathrm{C}\right)$ or more above or below $98.6^{\circ} \mathrm{F}\left(37^{\circ} \mathrm{C}\right)$. Also, your normal body temperature changes by as much as $1^{\circ} \mathrm{F}$ $\left(0.6^{\circ} \mathrm{C}\right)$ throughout the day, depending on how active you are and the time of day. Body temperature is very sensitive to hormone levels and may be higher or lower when a woman is ovulating or having her menstrual period.

\section{Appendix D: Blood Pressure Chart}

Use the blood pressure chart below to see what your blood pressure means. The blood pressure chart is suitable for adults of any age. (The level for high blood pressure does not change with age.)

Blood pressure readings have two numbers, for example 
140/90mmHg. The top number is your systolic blood pressure. (The highest pressure when your heart beats and pushes the blood round your body.) The bottom one is your diastolicblood pressure. (The lowest pressure when your heart relaxes between beats.)

The blood pressure chart below shows ranges of high, low and healthy blood pressure readings.

Blood pressure chart for adults

Using this blood pressure chart: To work out what your blood pressure readings mean, just find your top number (systolic) on the left side of the blood pressure chart and read across, and your bottom number (diastolic) on the bottom of the blood pressure chart. Where the two meet is your blood pressure.

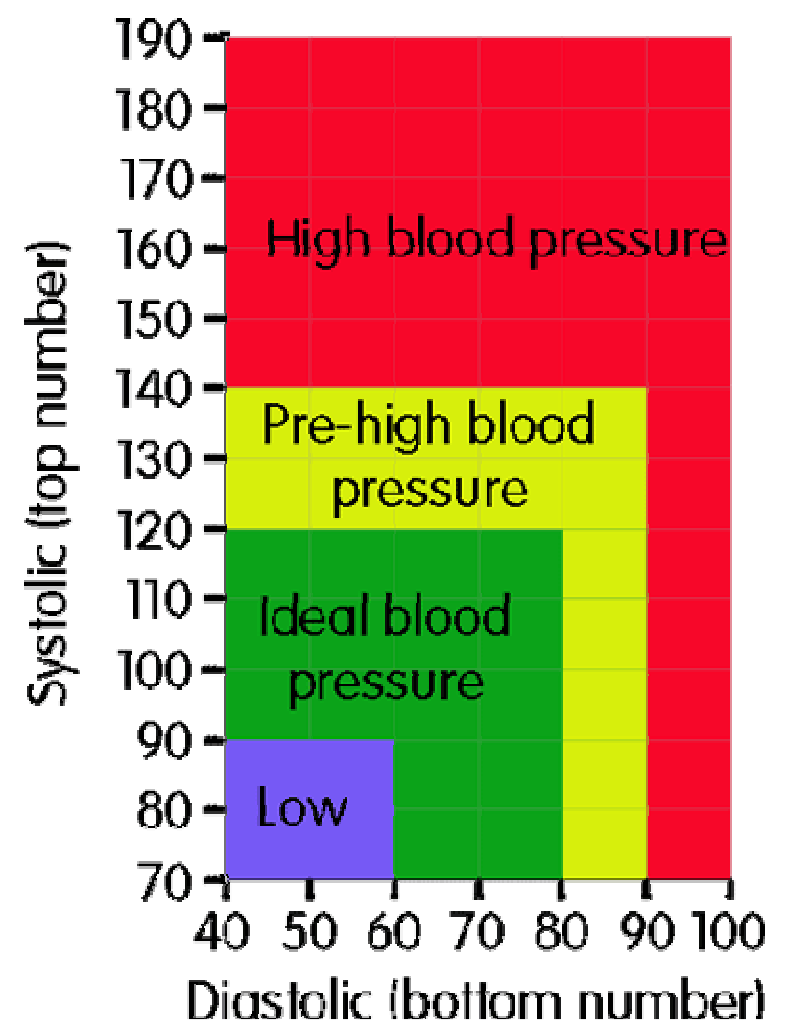

Appendix D Cont'd

What blood pressure readings mean

As you can see from the blood pressure chart,only one of the numbers has to be higher or lower than it should be to count as either high blood pressure or low blood pressure:

- 90 over $60(90 / 60)$ or less: You may have low blood pressure. More on low blood pressure.

- More than 90 over $60(90 / 60)$ and less than 120 over 80 (120/80): Your blood pressure reading is ideal and healthy. Follow a healthy lifestyle to keep it at this level.

- More than 120 over 80 and less than 140 over 90 (120/80-140/90): You have a normal blood pressure reading but it is a little higher than it should be, and you should try to lower it. Make healthy changes to your lifestyle.

- 140 over 90 (140/90) or higher (over a number of weeks): You may have high blood pressure (hypertension).Change your lifestyle - see your doctor or nurse and take any medicines they may give you. More on high blood pressure

So:

- if your top number is 140 or more - then you may have high blood pressure, regardless of your bottom number.

- if your bottom number is 90 or more - then you may have high blood pressure, regardless your top number.

- if your top number is 90 or less - then you may have low blood pressure, regardless of your bottom number.

- if your bottom number is 60 or less - then you may have low blood pressure, regardless of your top number.

\section{References}

[1] M. Weiser, "Ubiquitous computing" http://www.ubiq.com/hypertext/weiser/UbiHome.html., 2003

[2] U. Hansmann, "Design Personal Computer real- time and embedded systems Wireless". Springer- Verlag New York, Inc., New York, 2001.

[3] J. Burkhardt, "Pervasive Computing: Technology and Architecture of Mobile Internet Application"

Addison-Wesley Longman Publishing Co., Inc. Boston, MA, USA, 2001.

[4] P. E. N.V. Koninklijke, Ambient intelligence. http://www.research.philips.com/technologies/projects/ambint el.html., 2003

[5] S. Marzano, and E. Aarts, The New Every day. 010 Publishers, 2003.

[6] E. A. Lee. "Cyber physical systems: design challenges" Technical report, EECS Department, University of California, Berkeley, January (CPS Steering Group), 2008.

[7] Workshop Report. Foundations for Innovation in CyberPhysical Systems. http://events.energetics.com/NIST- CPS Workshop/downloads.html

[8] D.C. Stockwell, \& A. D. Slonim. Quality and safety in the Intensive Care Unit. J Intensive Care Med 2006 Jul; 21(4):199-210.

[9] M. Paolo. Formal verification of Medical user interface software in PVS, Queen Mary University of London, 2014.

[10] NAP Committee on Quality of Health Care in America IoM. 'To err is human: building a Safer Health System'. Washington, D.C.: National Academy Press, 2001

[11] M. Soares, J.I.F, Salluh,., F.A. \& Bozza, Current definitions of patient safety. In: Chiche, J. D, Moreno R, Putensen C, Rhodes A, editors. Patient Safety and Quality of Care in Intensive Care Medicine. Berlin: Medizinisch Wissenschaftliche Verlagsgesellschaft; p. 9-17. 2009.

[12] T. J., John, A New Evidence-based Estimate of Patient Harms Associated with Hospital Care Journal of Patient Safety Volume 9, Number 3. 2013

[13] R. Mohamed, and A. Khalid "Development of an expert system for Reducing medical errors" International Journal of Software Engineering \& Applications (IJSEA), Vol.4, No.6, November 2013 DOI : 0.5121/ijsea.2013.460329 
[14] R. J. Arney, J. Paul, L. Insup, R. Arnab, S., Oleg, and Z., Yi, Generic Infusion Pump Hazard Analysis and Safety Requirements Version 1.0, 2009

[15] S. Sriram, H., Hadjar, and L., Clayton. Model- Based Dependability Analysis of Programmable Drug Infusion Pumps University of Colorado, Boulder, CO, 2011.

[16] H. Vaishali, R., Philips, and R. Dev. Design for Reliability in Medical Devices Patient System Safety 978-1-4244-51036/10/\$26.00 @2010 IEEE, 2010

[17] B. C. Jeffrey, S. N., Ronald, D.L., Charlene, and M., Bucknam, Preventable anesthesia mishaps: a study of human factors. Qual Saf Health Care 2002;11:277-283 https://www.bu.edu/av/courses/med/05sprgmedanes thesiology/002/cooper\%20study.pdf,

[18] O. R. Selwyn, M. K. Gawande, P. Ann Louise, Y. Catherine,
A.B. Troyen, and M.C. David, Analysis of surgical errors in closed malpractice claims at 4 liability insurers. Harvard Risk Management Foundation and the Harvard School of Public Health, 2006

[19] C. H. Gaylene, M. H. Fanzca, M.S. Penelope, D.T. and T. Rowan. Barriers to Adverse Event and Error Reporting in Anesthesia. International Anesthesia Research Society, 2012 http://citeseerx.ist.psu.edu/viewdoc/download? doi=10.1.1.380.1686\&rep=rep1\&type $=$ pdf

[20] FDA. Infusion Pump Improvement Initiative Center for Devices and Radiological Health U.S. Food and Drug Administration 2010.

[21] E. Joan, and L. Helen "Insulin Pump Workbook" (n.d) 5 www.diabeteseducation.net/pdf/resources/insulin_pump_workbook.pdf. 